\title{
29. COVID-19 and the promise of food system innovation
}

\section{Corinna Hawkes}

One of the silver linings of any crisis is the innovation it produces. And when it comes to food, COVID-19 is no exception.

The evidence, anecdotal as it is, shows that lockdowns around the world have had a profound impact on the markets, transport, and labor supply needed to produce, distribute, and sell nutritious foods. With reports of vegetables rotting in the fields and milk being thrown away while people go without, a clear mismatch has emerged between supply and demand.

But as things have closed down, new spaces have opened up. Innovations driven by government, business, and communities targeting production, distribution, markets, and consumers have proliferated to enable food to get to people who need it in new ways. Crisis often necessitates new actions for short-term solutions. But given the longer-term problem of undernutrition and overweight around the world, and the ongoing conversation about how food systems need to change, it's worth asking: do these innovations tell us anything about what is possible and beneficial for food systems transformation toward nutritious, healthy diets for all?

Let's look first at the innovations themselves. Digital innovations have been noteworthy in enabling producers to conduct their businesses in new ways. In China, where the pandemic began, the Chinese Agricultural Product Market Association has been working with e-commerce businesses and mobile chat groups to provide online platforms to help supply meet demand; suppliers post information about what foods they have and buyers do likewise about what they need. Government has also simplified registration procedures and provided training on sales and consumer-oriented marketing to make it easier for farmers to set up e-enterprises for their products. In India, the National Informatics Centre created the Kisan Rath mobile app to help farmers and traders find vehicles to move their fruits and vegetables to market. In Malawi, farmers are reportedly adding value to products otherwise lost - tomatoes into pastes, for example - and using online advertising platforms to get the word out. In Oman, the Ministry of Agriculture and Fisheries has established an online auctioning platform to enable electronic bidding for fish.

Innovations in distribution have likewise been driven by government, as well as by communities themselves. In India, an amendment to the Agriculture Produce Market Committee Acts now allows farmers to sell their harvests from multiple locations and to any buyer, rather than just in designated markets. In Fiji, the Agriculture Marketing Authority stepped in to buy fresh foods direct from suppliers unable to travel to market, selling them on at no added cost to market vendors. In Nepal, communities established "agri-ambulances" to get vegetables from farm to market. 
Elsewhere, there have been innovations in point-of-sale. In Quito, Ecuador, sales from the city's extensive network of urban and peri-urban agriculture have been diversified to include third-party transactions and basket sales direct from the gardens. In Addis Ababa, Ethiopia, the government has provided a renovated stationary bus as a venue for urban farmers to provide direct market access to local people.

For people going short on food, new methods are likewise being used to supply food, vouchers, and meals. Innovations at the urban level are of particular note. From the food deliveries in Lima, Peru, to the community kitchens in Freetown, Sierra Leone, and Masiphumelele, South Africa, communities, governments, private enterprise, and funders are finding new ways to feed people. Other examples include vouchers for families formerly supported by the nationwide free school meals program in São Paulo, Brazil, and repurposed buses being used to deliver food in Wuhan, China. At the national level, it is reported that governments in the Pacific Islands and Sri Lanka are distributing seeds to encourage households to grow their own. Much more dominant are new social protection measures: the World Bank reports that as of June 12, 2020, 173 countries had enacted 621 new social protection measures, including cash transfers and in-kind food and voucher schemes - a vital lifeline to enable people in poverty to afford nutritious foods. Some have also taken measures to stabilize prices. Sri Lanka, for instance, is reported to have fixed the wholesale price of vegetables. New finance measures have been taken with potential to support small food enterprises and food production.

Needless to say, it's not known if these innovations are working. Doubtless, some are not. Others will be mired in political conflict; plenty more will not go far enough. Others may even be inappropriate - such as reports of junk food in delivery schemes - or misplaced. Elsewhere, doors to novel ideas remain firmly shut. So this is not a case of championing innovations for innovations' sake, and endorsing them without a critical eye. Rather, it is a case of assessing what can be learned from them about what is possible and beneficial for food systems change.

Here are three ways these innovations show the way forward. There are likely more.

First, food systems solutions to ensure the right kind of food gets to those most vulnerable are possible. During COVID-19, the bureaucratic, financial, logistical, and technological reasons that always seemed to make actions impossible or improbable have fallen away. This shows, at its heart, that it is a political choice of whether to act or not. When there is a will, change is possible.

Second, concerted, creative, and cross-sectoral intervention is needed to get food systems working for better diets. It's not something that can simply be left to happen without a clear plan. Important as government is in these interventions, innovation also needs to involve communities, businesses, and partnerships. Creative thinking is needed to find the right solution from the diversity of possible innovations; this is not the time to fall back into pre-held assumptions about how food systems ought to work. Solutions can come in the form of hard regulation, for example, as well as business-driven solutions, through local markets as well as global ones.

Third, innovation is a huge opportunity to build evidence for the way forward. COVID-19 has provided a real-life innovation lab, a testing ground for big ideas. Test, fail, succeed, learn, change. What is working (or not) and why? What can we learn from this to redesign food systems? Experimenting our way to the future can and should be a way forward. A next step should be to assess what can be 
learned about what works (and what does not) and which innovations show most promise in effecting food systems change at different levels.

COVID-19 has disrupted food systems everywhere. But it has also provided an unprecedented opportunity for innovation, a space in time when immediate needs have spurred responses never seen before, a base on which to redesign food systems for the better.

Originally published June 18, 2020. 